\title{
The Impact Of Changing Technology: The Case Of E-Learning
}

Nadia Yusuf, Ph.D., King Abdul-Aziz University, Kingdom of Saudi Arabia Nisreen Al-Banawi, Ph.D., King Abdul-Aziz University, Saudi Arabia

\begin{abstract}
For centuries, education has relied on classroom methods, but technology-enhanced learning can potentially bring about a revolution in learning, making high-quality, cost-effective education available to a greater number of people. The basic advantages of e-learning include anytimeanywhere access to learning, cost reductions, ability to reach larger markets, more effective learning with personalized instructions, and flexibility. For the full potential of e-learning to be realized, however, the content, services, and systems from different suppliers all need to work together. This paper provides an overview of the benefits and limitations of e-learning as well as its cost-effectiveness. The continual advances in information technology as well as software-based training and education are rapidly offering a cost-effective and flexible alternative to traditional face-to-face learning. With the introduction of e-learning, students are empowered to embark on active, independent learning. They can access course information and perform research with the help of this virtual space provided using the Internet. Consistency, fast deployment, and simple evaluation are all attractive features of e-learning, but the most compelling reason to consider the introduction of e-learning may be the significant reduction in costs associated with education. Once developed, the online guidance component can be used many times with minimal costs. Students can also go through the training process repeatedly to ensure maximum effective learning.
\end{abstract}

Keywords: Education; E-learning; Internet; Cost-effectiveness; Instructors

\section{INTRODUCTION}

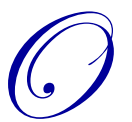

ne important factor that is increasing the need and development of distance education and e-learning is the fast evolution of technology and society in general (Hjeltnes, 2004). The combination of education with work and family has played an important role in promoting the development of open and flexible distance education. However, the current generation perceives the emergence of online education to be disadvantageous to the distance education system of previous generations (Corsaro et al., 2009). There is no question that a major shift is taking place - a move away from teacher-centered curricula towards learner-centered searching for the relevant study resources as needed. Previously, course content was often uninspired, boring, and failed to connect with the learner. Thus, it was ineffective in conveying its intended learning goals. The learning experience relies on the methods used by the faculty to convey information to students, who are bound to think within the boundaries of the course, being unsure as to how to enter and navigate around the course material. With e-learning, however, we can remove major expenses, such as travel costs, lost hours, training salaries, catering, and training materials. Businesses in the US, for example, spend an average of $\$ 1,202$ on training each employee every year (Leonard, 2008).

E-learning has grown dramatically (Bares, 2008). The use of self-study e-learning now accounts for $20 \%$ of student hours, up from 15\% last year. Related to this, this year's study has also shown a sharp increase in new web-based and collaborative learning resources, including podcasts, blogs and wikis. "E-learning," or educating employees via Internet coursework, has become popular in the financial services, with some banks claiming to have saved a lot of time and money. There is a downside nevertheless: employees who are not required to show up for class at a given time may simply neglect studying. In addition, some system administrators find that the software 
required for e-learning is not compatible with the learning-management systems used to supervise employees' progress with training. What has won banks over, however, is the ability for employees to log in to training sessions at their convenience (Costanzo, 2003).

\subsection{All Began with a Computer}

Our world is changing so rapidly each day that at times what is considered an innovation today becomes redundant tomorrow. Technologies emerge and evolve every moment, and we are quick to adapt or abandon them depending on their assigned use. One such revolution began in the late 1960s with the advent of a room-sized computer, which today sits in the palm of our hands. Multimedia CD-ROMs introduced in the early 1990s allowed us to develop programs with color, action, and interactivity. These were considered to be a major advance over the text on monochrome screens, which had characterized educational computing in the 1980s.

\subsubsection{The Advent of the "Internet"}

The introduction of the 'world wide web' in the early 1990s allowed resources from anywhere in the world to be accessed through universal resource locators (URLs). However, the Internet was a step backwards in terms of animation and interactivity because of the slowness of computers, modems, and the network at the time of its introduction (Demiray, 2011). It is only now that the capabilities of networked computers are approaching the level necessary to replicate the quality of e-learning that was possible using CD-ROMs. Consequently, this is changing the world of education by eliminating boundaries and barriers to make knowledge more easily accessed and available more universally. Education has been brought to the forefront, as societies all over the world not only realize the significance of education, but also invest a large amount into it

Education must be considered as a key investment in modern economies because, as previously seen, within the framework of a knowledge-based economy, there are strong and positive correlations between economic activity and education in explaining economic growth. E-learning can contribute to these advantageous dynamics by increasing access to education in society as a whole, thus avoiding the traditional constraints related to space, time, and the pace of teaching and learning systems, and by allowing many people who would otherwise not enroll in courses to have access to education (Carnevale, 2000; Ben Youssef \& Ragni, 2008).

\subsubsection{Greater Demand for Greater Numbers of People}

Coinciding with this revolution are the population explosion and increased knowledge. Indeed, knowledge has increased beyond learners' capacities to deal with all relevant kinds of information. These developments pose a challenge to education and, in particular, to the problems caused by increasing learner demand and the shortage of instructors, especially in higher education. The impact of these conditions calls for research on the possible options for learning and thus, requires educational institutions to develop efficient and effective systems to meet the demands of communities driven to attract tremendous scientific and technological progress. Therefore, educational communities must remain feasible for growth in the midst of global market competition and they must also benefit from the information and computer technology (ICT) revolution by employing it in order to respond to contemporary pressures (Algahtani, 2011).

\subsubsection{Evolution}

Accordingly, new ways of teaching and learning have begun to emerge globally, the most important of which is e-learning. E-learning has become a reality that is impossible to ignore, especially for those working in the educational sector. The necessity to know about the concerns of e-learning, its related concepts, skills, tools, and so forth drives this development forward. In this context, researchers will certainly rate the computer as the greatest invention in human history in terms of facilitating global communication. The combination of computers with knowledge has now opened up the education field to the entirely new concept of E-learning. However, before exploring this subject further the meaning and definition of the term "e-learning" needs to be discussed. 


\subsection{Defining e-Learning}

E-Learning refers to the employment of information and communication technologies to support the development and delivery of learning in academic and professional development institutions. E-Learning is used widely with other terms such as online learning, technology-mediated learning, web-based learning, computer-based learning, etc.

\subsubsection{How Does E-Learning Function?}

The shift from teacher-centered to student-centered learning is presented in the following illustration in Figure 1 below.

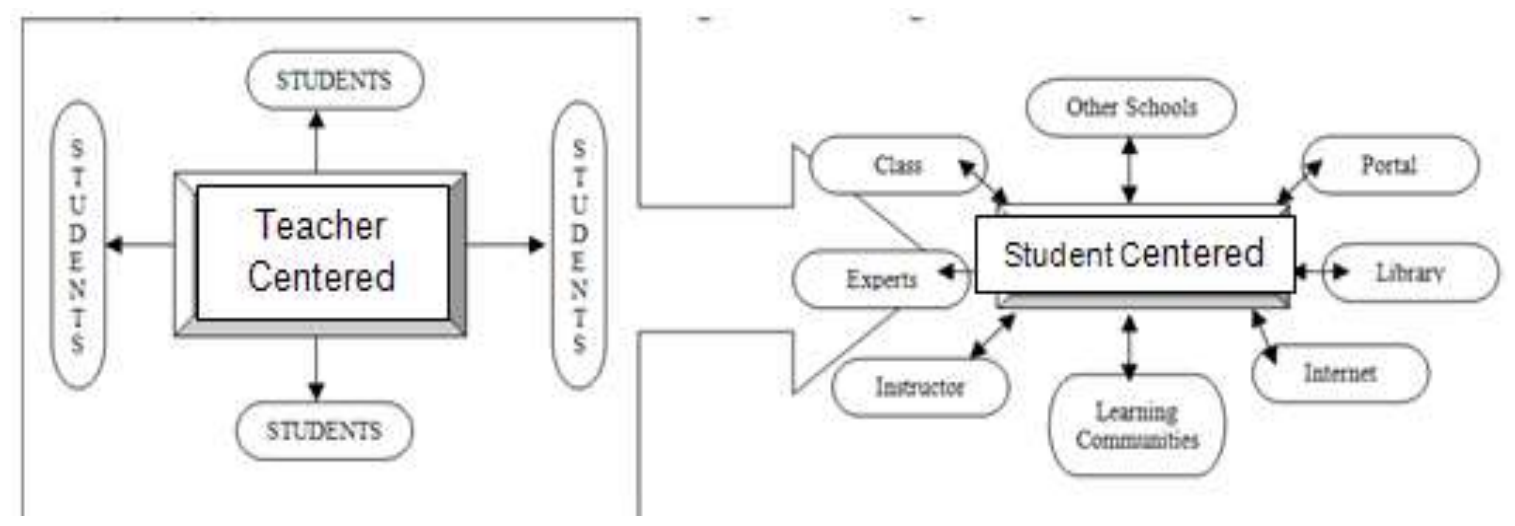

Figure 1. The shift from teacher-centered to student-centered learning

New methods of teaching and learning have begun to emerge globally, the most important being e-learning, which is promoting this shift from teacher-centered to student-centered learning, as shown in Figure 1. The widespread use of ICT has led to new communication channels and made information more accessible, while the Internet has changed learning methods (Ryder \& Wilson, 1996). Indeed, the revolutionary thrust of ICT is derived from the alliance of the two types of rapidly developing technology: personal computers that are small and affordable, including devices such as tablets and smart phones, and wired and wireless networks, providing an exchange between devices whether near or far (Al-Fahad \& Al-Mosa, 2002). Thus, the Internet provides new and interesting opportunities for learning (Al-Salem, 2004), supported by the use of interconnected multimedia devices. Now, as seen, e-learning is clearly taking the lead in the global educational sector given its distinct advantages (Algahtani, 2011, pp. 2-3). For this reason, governments and people across the world are rapidly adopting e-learning to such an extent that it stands a chance of emerging as the preferred mode of education in the years to come.

\section{ADVANTAGES AND DISADVANTAGES}

As e-learning saves both time and money, and enables mass training, it attracts new companies needing to undertake professional training. While the e-learning system has many benefits, it also has certain limitations.

\subsection{Advantages of E-Learning}

As e-learning evolved out of two developments - one in the field of knowledge and the other in the realm of education - we can clearly identify its key characteristics. These characteristics have enabled e-learning to provide credible and strong competition to the methods of conventional education in a very short period. Students who are able to draw their own meaning or interpretation and apply teachings to their lives may gain the most from E-learning. E-learning creates a student-centered learning environment as noted by R. Gravoso (2008) who states, "Efforts to improve students' learning outcomes have suggested the need to embed the use of educational technology in a learner-centered learning environment where students construct their own meanings" (p.109). Elearning may offer some students an environment that allows for a better understanding of the materials. 
Research shows that effective education is comprised of a mix of the learner's memory and how well he/she will retain information, how involved he/she is in classroom activities and prior knowledge of the topic.

The ability to remember teachings long after the period of learning is quite significant. Willis (2007) believes that, "When memory and retention brain research are applied to the classroom, they not only drive the learning process, but also allow educators to energize and enliven the minds of students" (p.6). A student, who remembers information long after it has been taught, has been taught effectively.

Involving students in class activities and discussions engages them and heightens their desire to learn the subject. According to Bobbitt, Inks, Kemp, and Mayo (2000), instructors should be the designers of a learning environment in which students are active participants in the learning process (p.15). In this way, the teacher may move from a teacher-focused to a learner-centered style of teaching.

Having prior knowledge of a subject will allow the learner to obtain a deeper understanding of the content and have an easier time recalling information that is stored in memory. Vanderbilt (2005) emphasizes that, "When students have some knowledge of a topic, it is easier for them to make connections and learn new information" (p.1). Having some prior knowledge of a subject area helps learners relate to past experiences; thereby, understanding with a much clearer thought process of what is being taught.

\subsection{Disadvantages of E-Learning}

E-learning has without doubt certain limitations. If online courses attract students who would otherwise not have attended higher education, this trend is important from a policy perspective, as it has a positive effect on the increase of human capital. Learners with low motivation or bad study habits may fall behind. Without a proper class, the students may get lost or confused about the course activities and deadlines. Students may feel isolated from the instructor and classmates. Instructors may not be available when students are studying or need help. Slow internet connections or older computers may make accessing course materials difficult.

\section{WHAT IS THE FUTURE OF E-LEARNING?}

The new learning landscape is a multichannel learning environment that can be seen as a "complex adaptive system". For the most part, this environment is "self organizing" and because of that it is difficult to exactly predict how it is all going to turn out in the next decades (Machado and Demiray 2012). However, there is no question that a major shift is taking place, a shift away from teacher-centered curricula towards learner-centered investigating of relevant learning resources as needed (Demiray, 2012). The shift is from instructor controlled classroom learning and instructor controlled e-learning to a mix of approaches that includes instructor control when appropriate (for specific certifications, for example) along with many different types of resources and requirements from which learners can choose and explore. Emerging e-learning will not be simply mixed with "face-to-face" learning to form blended learning (Dagiene and Kurilovas 2010).

Rather, all learning will be multichannel learning. The "e" in e-learning will gradually disappear, as electronic support for learning by any means becomes invisible and taken-for-granted (Woodill \& Oliveira, 2006). As stated, e-learning stand a very real chance of emerging as a conventional mode of education. Furthermore, elearning continues to evolve with new delivery methods - to PDA or mobile phone (called M-Learning) and via blogs, wikis, Podcasts, and easier to-use tools. There is also a trend seen in the transition from training to learning that leverages the power of the Internet to go beyond e-Learning through knowledge management, competency management, and performance support and to HR processes like performance management, talent management, succession planning, and hiring. Web 2.0 (and e-learning 2.0) technologies are driven by collaboration. It is the next phase of e-Learning (Clarey, 2007, pp 29).

\subsection{Quality and Evaluation of E-Learning}

Defining quality in e-learning and what should be considered when evaluating the quality of e-learning has been developed during the last 15 years. Despite the important contribution of each of those studies, a complete 
framework for evaluating the quality of e-learning couldn't be addressed. Developed frameworks either describe the quality of e-learning program with an importance on the classroom environment only or overlooked some important aspects such as the impact of the institute on the quality of E-learning programs (Cashion and Palmieri, 2002). ELearning has been set by governing or accrediting bodies which have developed quality standards, principles or frameworks. Such standards however, were developed to help institutions plan for their E-learning (Cashion and Palmieri, 2002) or as a self-assessment tools, so they usually address in general perspective academic standards, quality standards, standards of competence, organizational standards and service standards (Harvey, 1999).

Researchers can help stakeholders and institutions make sensible decisions about the question that result from e-learning (Madinach, 2005). Methodologies must be designed to examine how technology enables or facilitates teaching and learning activities in the context of e-learning. It would be remiss to look only at the medium and then make comparisons across various delivery mechanisms. Technology is only a tool. The technology becomes necessary but not a sufficient condition. The focus of examination therefore becomes the interaction among several important levels of variables with the technology.

\section{COST EFFECTIVENESS}

The two major changes causing traditional training to move towards e-learning are: the sharp cuts in training budgets and the capacity of e-learning to provide much more effective training. Below is discussed the cost analysis of education relative to face-to-face or e-learning training, where costs may differ. Similarly, the travel costs occur only when the course is not delivered internally.

\subsection{Cost Formula}

The cost formula is based on fixed costs, variable costs, and the total number of participants. Costs are either fixed or variable in relation to the number of participants. Fixed costs, such as course development costs, occur independently of the number of participants (Gertz, 2010). This means that the total fixed cost remains the same, no matter how many people join the course. Thus, the fixed cost per person actually decreases as the number of participants increases. Economists call this phenomenon "economy of scale." Variable costs, such as travel expenses, occur for each participant individually. This means that total variable costs increase along with the number of participants but the variable costs per person stay constant. Therefore, we can use the following formula to calculate the total cost of both face-to-face training and e-Learning:
Total Cost
$=\quad$ Fixed Cost
$+\quad$ Variable Cost
x No. of Participants

\subsubsection{Irrelevant Cost}

We need not include in our cost calculation those costs that are the same for both traditional and e-Learning solutions (e.g. the salary of the training manager). The reason for this is that we are comparing the changes in cost of substituting or blending an existing face-to-face training with e-Learning. Including these costs for both alternatives will yield the same result but will create more work than is necessary. When deciding whether to blend or substitute an existing face-to-face training with e-Learning, you should not include the costs which have already been paid for during the face-to-face training (sunk cost). For example, you have developed a face-to-face training for which now there are only variable costs (i.e. the trainer's salary). These development costs are considered sunk cost and can thus be ignored. For the new e-learning alternative, however, you should include these costs (Gertz, 2010). 


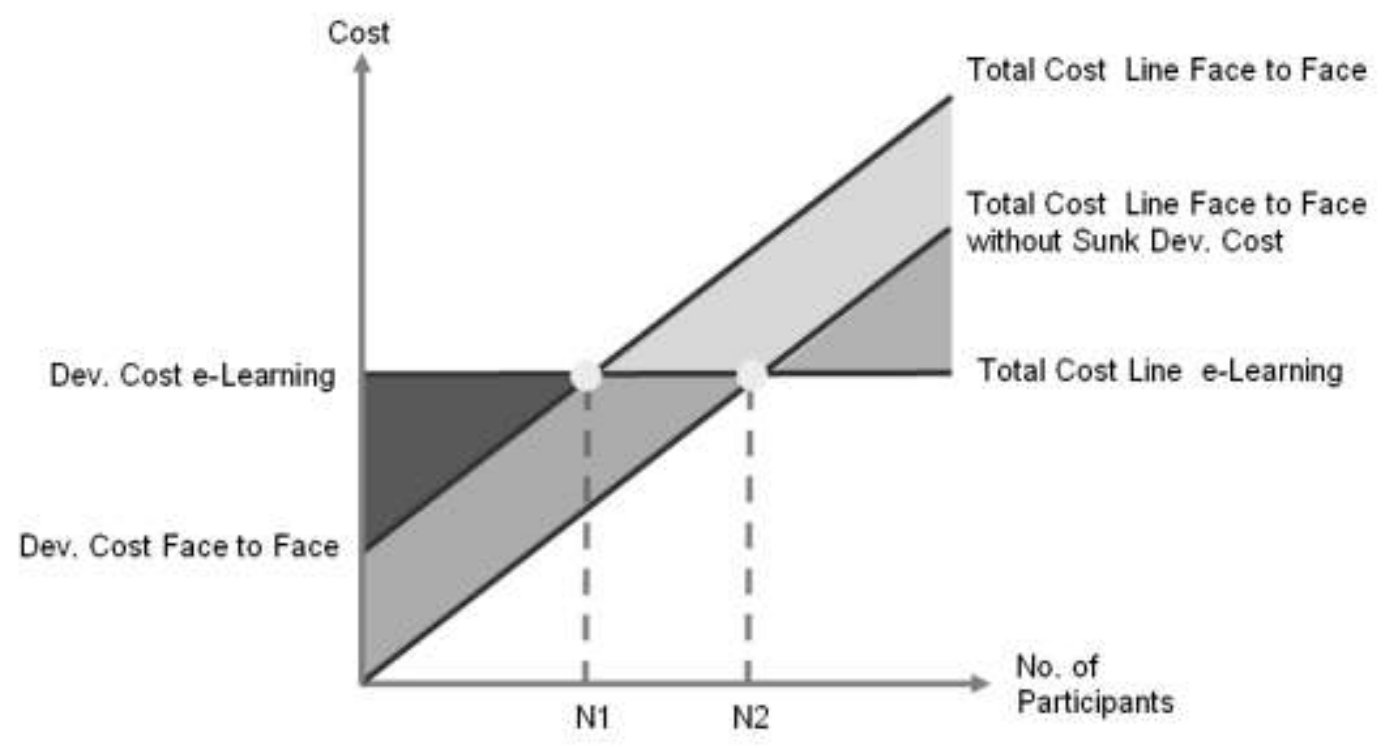

Figure 2. Cost comparison of personalized face-to-face training versus personalized e-learning course in relation to the number of participants.

Both courses have fixed development cost, as shown in the above Figure 2. The development cost of faceto-face training is clearly lower than that of e-Learning. On the other hand, once developed, the e-Learning course does not incur any further costs. Therefore, the total cost line for e-Learning is horizontal. The traditional course, however, contains such variable costs as the cost of the trainer. Consequently, the total cost line of the face-to-face course continues rising after development (Gertz, 2010). When a particular number of participants are reached at $\mathrm{N} 1$, the total cost line of the face-to-face training intersects with that of the e-Learning training. So after this number is reached, the total cost of e-Learning is less than that of a traditional training. From N2 on, the additional cost of eLearning is less than the additional cost of continuing the face-to-face training. The levels of variables include institutional infrastructure, pedagogical or teacher processes, and student learning processes. Researchers must capitalize on and begin to understand the impact of the unique characteristics of the technological environment, such as anywhere/anytime/any pace access, interactivity, and accessibility to enormous amounts of resources that heretofore have not been possible in higher education (Madinach, 2005).

\section{CONCLUSION}

E-Learning is still in its growth phase and holds tremendous potential for developing countries. However, it requires huge amounts of financial and human resources input. The growth of e-learning is almost wholly dependent on the advancements in corresponding technologies. E-learning should not be simply a current incarnation of correspondence courses if its implementation is to utilize fully the affordances of technology (Madinach, 2005). Models to judge the effectiveness of e-learning are still to be developed and perfected. Although there are many advantages associated with e-learning, the disadvantages too need to be eliminated before its full potential can be realized. We have seen that it is important to base the total cost calculations on variable costs, fixed costs, and the number of participants. Finally, there remains Cost-Benefit Analysis: in this approach, all outcomes are translated into monetary values. The popular training ROI is actually one form of Cost Benefit Analysis (Gertz, 2010). Going by the trends witnessed in its growth, it is possible for e-learning to become a conventional form of education in the years to come. E-Learning clearly indicates a shift from instructor controlled classroom learning and instructor controlled e-learning to a mix of approaches that includes instructor control when appropriate (Dagiene and Kurilovas 2010). In a world where more is expected of individuals and organizations, with budgetary pressures continually increasing, e-learning may offer a viable alternative to traditional training. 


\section{AUTHOR INFORMATION}

Dr. Nadia Yusuf (Indian), born in Riyadh, Saudi Arabia, completed her academic studies at Aligarh Muslim University, India, before moving back subsequently to settle in Jeddah. Her doctoral thesis on economics examined the role of leading banks in financing the agricultural sector in India, with reference to the Aligarh District. Presently, Dr. Yusuf works as an Assistant Professor, at Economics Department in King Abdul-Aziz University, Jeddah, K.S.A, and teaching students using a systematic plan of lectures, demonstrations, discussion groups, laboratory work, shopping sessions, seminars, case studies, field assignments, and independent or group projects. Corresponding Author. E-mail: nadia112yusuf@ hotmail.com (Corresponding author)

Dr. Nisreen Al-Banawi, Head of the Department of Economics at King Abdul-Aziz University, is a member of Saudi's Economics Association and Saudi Association for Population Studies. Her teaching experience since 1989 is in micro- and macro-economics, labor, mathematical, and healthcare economics. She has authored various articles in the field of maritime economics.

\section{REFERENCES}

1. Alfahad, F. and Almosa, A. (2002). The Role of Communication Services in the Internet in The Development of Education Systems in Higher Education Institutions. Research Centre, Saudi Arabia, Riyadh: King Saud University.

2. Algahtani, A. F. (2011). Evaluating the effectiveness of the e-learning: Experience in some universities in Saudi Arabia from male students' perceptions (Doctoral thesis). Durham University, Durham City, United Kingdom.

3. Alsalem, A. (2004) Educational Technology and E-learning, Riyadh: Alroshd publication.

4. Bares, A. (2008). Compensation force (blog). Companies Spend an Average of \$1,202 per Employee on Training. http://compforce.typepad.com/compensation_force/2008/02/companies-spend.html

5. Ben, Y. A. \& Ragni, L. (2008). "Uses of Information and Communication Technologies in Europe's Higher Education Institutions: From Digital Divides to Digital Trajectories". In: "The Economics of E-learning" [Online Monograph]. Revista de Universidad y Sociedad del Conocimiento (RUSC). Vol. 5, No. 1, UOC.

6. Bobbitt, L. M., Inks, S. A., Kemp, K. J., \& Mayo, D. T. (2000). Integrating marketing courses to enhance team-based experiential learning. Journal of Marketing Education, 22, 15-24.

7. Carnevale, D. (February 28, 2000). Jones International U. to offer accredited online MBA.

8. Cashion, J. \& Palmieri, P. (2002). 'The secret is the teacher': the learner's view of online learning. Adelaide: NCVER.

9. Corsaro, S. Angelis. P.L. Gaurracino, M.R. Marino, Z. Monetti, V. Perla, F. Zanetti, P. (2009). Kremm: an e-learning system for mathematical models applied to economics and finance. Journal of eLearning and Knowledge Society, 5(1), 221-230.

10. Costanzo, C. (2003). Does 'e-learning' live up to cost cutting promise? American Banker, the Financial Services Daily, CLXVII No. 236. Published on December 10, 2003.

11. Clarey, J. (2007). E-Learning 101: An Introduction to E-Learning, Learning Tools, and Technologies, April 2007, Brandon Hall Research, USA.

12. Dagiene, H. and Kurilovas, E. (2010). Cases of Challenges Facing E-Learning and National Development: Institutional Studies and practices. Dr. Ugur Demiray (Eds.), Vol-1. ISBN: 978-975-98590-8-4. Anadolu University, Eskisehir, Turkey.

13. Demiray, U. (2011). Distance education and eLearning practices: In Turkey and Eastern countries. Anadolu University, Eskisehir, Turkey.

14. Demiray, U. (2012). E-Learning in Ugur Demiray's opinion. Anadolu University, Eskisehir.

15. E-Learner web-page (year), Advantages and disadvantages of eLearning. Iowa State University. http://www.dso.iastate.edu/asc/academic/elearner/advantage.html

16. Gertz, T. (March 12, 2010). Evaluating e-learning investments with cost-effectiveness analysis. www.learningsolutionsmag.com

17. Gravoso, R., Pasa, A., Labra, J. \& Mori, T. (2008). Design and use of instructional materials for studentcentered learning: a case in learning ecological concepts. Asia-Pacific Education Researcher, 17(1), 109120.

2013 The Clute Institute http://www.cluteinstitute.com/ 
18. Harvey, L., 1999, 'Quality in higher education', paper at the Swedish Quality Conference, Goteborg, November 1999. http://www.bcu.ac.uk/crq/publications/goterburg.pdf, accessed 9 October 2012.

19. Hjeltnes, T. A. (2004). Cost effectiveness and cost efficiency in e-learning. TISIP. Borje Hansson, Mid Sweden University, Sweden.

20. Leonard, O. Karen. (2008). The Corporate Learning Factbook 2008: The U.S. Corporate Training Market. Published on $1 / 23 / 2008$.

21. Machado, C and Demiray, U (2012). E-Learning Practices Revised: A Compiling Analysis on 38 Countries, E-Learning - Long-Distance and Lifelong Perspectives. Dr. Elvis Pontes (Ed.), ISBN: 978-95351-0250-2, InTech. http://www.intechopen.com/books/e-learning-long-distance-and-lifelongperspectives/elearning-practices-revised-a-compiling-analysis-on-38-countries

22. Madinach, E (2005). The Development of Effective Evaluation Methods for E-Learning: A Concept Paper and Action Plan. Teachers College Record, Vol. 107, No. 8.

http://www.eric.ed.gov/ERICWebPortal/search/detailmini.jsp? nfpb=true\&_\&ERICExtSearch_SearchValu e 0=EJ694411\&ERICExtSearch_SearchType_0=no\&accno=EJ694411

23. Ryder, M. and Wilson, B. (1996). Affordances and Constraints of the Internet for Learning and instruction, The Association for Educational Communications Technology Indianapolis, [online]. http://www.cudenver.edu/ mryder/aect 96.html [Accessed 7/4/2008].

24. Vanderbilt, K. (2005). Connecting learning: brain-based strategies for linking prior knowledge in the library media center. School Library Media Activities Monthly, 21(7), 21-3.

25. Willis, J. (Annual 2007). Brain-based teaching strategies for improving students' memory, learning, and test-taking success. Childhood Education, 83(5), 310-316.

26. Woodill, G., \& Oliveira, C. (2006). Mashups, SOAP, and services: Welcome to Web hybrid e-learning applications, www.learningsolutionsmag.com 